Moffett, Kevan B.; Robinson, David A.; Gorelick, Steven M. 2010 Relationship of salt marsh vegetation zonation to spatial patterns in soil moisture, salinity and topography. Ecosystems, 13. 1287-1302. 10.1007/s10021-010-9385-7

(c) Springer Science+Business Media 2010

This version available http://nora.nerc.ac.uk/8699/

NERC has developed NORA to enable users to access research outputs wholly or partially funded by NERC. Copyright and other rights for material on this site are retained by the authors and/or other rights owners. Users should read the terms and conditions of use of this material at http://nora.nerc.ac.uk/policies.html\#access

This document is the author's final manuscript version of the journal article, incorporating any revisions agreed during the peer review process. Some differences between this and the publisher's version remain. You are advised to consult the publisher's version if you wish to cite from this article.

The original publication is available at www.springerlink.com 


\section{ECOSYSTEMS 然 Springer}

\section{Relationship of salt marsh vegetation zonation to spatial patterns in soil moisture, salinity and topography}

\begin{tabular}{|r|l|}
\hline Journal: & Ecosystems \\
\hline Manuscript ID: & draft \\
\hline Types: & Original Article \\
\hline Date Submitted by the & \\
Author: & $\begin{array}{r}\text { Moffett, Kevan; Stanford University, Environmental Earth System } \\
\text { Science } \\
\text { Robinson, David; University of the West Indies, Food Production } \\
\text { Gorelick, Steven; Stanford University, Environmental Earth System } \\
\text { Science }\end{array}$ \\
\hline Key Words: & $\begin{array}{l}\text { pattern, salt marsh, vegetation, zonation, edaphic, wetland, } \\
\text { geophysics, ECa, Q-DEMl }\end{array}$ \\
\hline &
\end{tabular}

\section{ScholaroNE \\ Manuscript Central}




\title{
Relationship of salt marsh vegetation zonation to spatial patterns in soil moisture, salinity and topography
}

\author{
Kevan B. Moffett ${ }^{1, *}$, David A. Robinson ${ }^{2, \dagger}$, and Steven M. Gorelick ${ }^{1}$ \\ ${ }^{1}$ Dept. of Environmental Earth System Science, Stanford University, Stanford, CA 94305 USA \\ ${ }^{2}$ Dept. of Geophysics, Stanford University, Stanford, CA 94305 USA
}

\begin{abstract}
Author Contributions: DAR, SMG, and KBM conceived of and designed the study. DAR and KBM performed field work and processed the data. KBM and SMG developed the analytical methodology. KBM analyzed the data and wrote the article.

* Corresponding author. E-mail: moffett@stanford.edu. Fax: 650-725-0958.

${ }^{\dagger}$ Present address: Dept. of Food Production, University of the West Indies, St. Augustine, Trinidad and Tobago


Salt marsh spatial patterns and zonation

Moffett, Robinson, Gorelick

\section{AiBdFTBACE.}

2 An intertidal San Francisco Bay salt marsh was used to study the spatial relationships between

3 biotic and abiotic ecosystem components: specifically, between vegetation patterns and

4 hydrologic and edaphic variables. Multiple abiotic variables were represented by six metrics:

5 elevation, distance to major tidal channels and to the nearest channel of any size, edaphic

6 conditions during dry and wet circumstances, and the magnitude of tidally-induced changes in

7 soil saturation and salinity. A new approach, quantitative differential electromagnetic induction

8 (Q-DEMI), was developed to obtain the last metric. The approach takes the difference in soil

9 induction from dry to wet conditions and converts that information to quantitative maps of

10 tidally-induced changes in root zone soil water content and salinity. The result is a spatially

11 exhaustive map of edaphic changes throughout the ecosystem. Spatially-distributed data on the

12 six metrics were used to explore two hypotheses. 1) Multiple abiotic variables relevant to

13 vegetation zonation each exhibit different, uncorrelated, spatial patterns throughout an intertidal

14 salt marsh ecosystem. 2) Vegetation zones and habitats of individual plant species are uniquely

15 characterized by different combinations of key metrics. The first hypothesis was supported by

16 observed, uncorrelated spatial variability in the metrics. The second hypothesis was supported by

17 binary logistic regression models that identified key vegetation zone and species habitat

18 characteristics from among the six metrics. Based on results from 108 models, the Q-DEMI map

19 of saturation and salinity change was the most useful metric for distinguishing different

20 vegetation zones and species habitats in the salt marsh.

21

22 KEYWORDS

23 pattern, salt marsh, vegetation, zonation, edaphic, wetland, geophysics, ECa, Q-DEMI 
Salt marsh spatial patterns and zonation

Moffett, Robinson, Gorelick

\section{INTRODUCTION}

2 The segregation of a few dominant plant species into distinctive zones is characteristic of

3 intertidal salt marshes. Each zone comprises a distinctive macrophyte assemblage and may also

4 uniquely sustain other species of concern. For example, stands of native Spartina foliosa densely

5 dissected by tidal channels San Francisco Bay support endangered Rallus longirostris obsoletus

6 (California Clapper Rails), but endangered Reithrodontomys raviventris (Salt Marsh Harvest

7 Mice) favor largely monospecific and undissected Salicornia virginica flats (USFW 2008). The

8 nature and causes of this ecologically important vegetation zonation have been studied for

9 decades with gradient analyses and paired plot, mesocsosm, or transplant studies. Such studies

10 have determined that the causes of salt marsh vegetation zonation are both physical, determined

11 in part by variability in soil (edaphic) and tidal conditions (Pennings and others 2005), and

12 biological, the result of interspecific resource competition and biological response to periodic

13 disturbance (Bertness and others 1992; Emery and others 2001; Pennings and Callaway 1992),

14 even as the specific patterns and species vary regionally (Peterson and others 2008).

15 At the ecosystem scale, it remains a challenge to explain salt marsh vegetation patterning

16 despite knowledge of specific zonation mechanisms at the plant scale. Characterization of the

17 spatial variability of vegetation within salt marsh ecosystems has thus far relied heavily on

18 metrics of relative landscape position such as elevation and distance to tidal channels; however,

19 these geographic metrics, alone, have been insufficient predictors of salt-marsh vegetation zones

20 (Zedler and others 1999, Silvestri and others 2005). Although remote sensing has been used to

21 map spatial patterns of tidal channels (e.g., Marani and others 2006) and marsh surface

22 elevations (e.g., Sadro and others 2007) in relation to salt marsh vegetation, such maps are highly

23 nonspecific, failing to distinguish unique and consistent salt marsh vegetation habitat 
Salt marsh spatial patterns and zonation

Moffett, Robinson, Gorelick

6247 Ehgractenistwibs. Probabilistic models based on geographic metrics (e.g., Sanderson and others,

25 2001) fare somewhat better, but the fraction of marsh vegetation cover predicted correctly is

26 greatly skewed by very high or very low coverage by a given species. Part of the difficulty in

27 such analyses is that geographic metrics are only rough proxies for the combined effects of many

28 physical, chemical, and biological variables that contribute to salt marsh zonation.

29 In this study we explored two hypotheses about the spatial nature of multiple zonation-

30 relevant variables and their relationship to salt marsh vegetation distribution. First, we

31 hypothesized that different variables, such as tidal flood duration and direction, root zone soil

32 water content, and soil salinity, may each exhibit different spatial patterns in a salt marsh. The

33 patterns of such variables may have different characteristic spatial scales and gradients oriented

34 in opposing directions. Second, each plant species or zone may correlate with different

35 combinations of variables. For example, one species might grow among dry soil conditions or

36 high soil salinity, but not both; another species might not grow among dry or salty edaphic

37 conditions. Also, due to interspecific interactions, a zone dominated by one species may not be

38 characterized by the same variables as the total habitat range of the species. Prior to this study,

39 such concepts had not been tested in a spatially-distributed manner throughout a salt marsh; we

40 investigated these hypotheses on the basis of extensive data sets spanning the full range of

41 conditions within an intertidal salt marsh ecosystem.

42 We examined the first hypothesis by comparing the spatial patterns of six zonation-

43 relevant metrics: elevation, distance to major tidal channels and to the nearest channel of any

44 size, the soil saturation/salinity state during dry and wet marsh conditions, and the difference in

45 this edaphic state between conditions. The first three metrics are geographic measures of

46 landscape position and proxies for hydrologic processes relevant to salt marsh vegetation 
47 zonation. Elevation is commonly employed to represent the effects of flood/exposure duration

48 and surface water ponding. A location's distance to the nearest tidal channel represents the likely

49 direction of tidal flooding and groundwater drainage and directional tidal energy effects (e.g.,

50 sediment deposition). This study uniquely considered both distances to primary tidal channels,

51 typically identified from aerial imagery, and distances to small $(\sim 0.1-0.5 \mathrm{~cm}$ wide, rarely

52 mapped) surface drainage pathways hidden beneath the vegetation that we term microtributaries.

53 The remaining three metrics reflected soil properties under different hydrologic

54 conditions (dry and wet marsh soils) and the magnitude of change between conditions. The soil

55 properties considered, soil saturation, salinity, and texture, are known to contribute to salt marsh

56 zonation (Silvestri and others 2005) but previously could only be measured at points, prohibiting

57 extensive repeat sampling and marsh-wide analysis. Geophysical electromagnetic induction

58 (EMI) imaging of bulk apparent soil electrical conductivity (ECa) captures the combined state of

59 soil saturation, salinity, and texture in one ECa number (Friedman 2005, Rhoades and others

60 1999) and can be surveyed quickly over a large area. EMI has been used to investigate patterns in

61 soil properties (e.g., Lesch and others 2005, Robinson and others 2009) but its potential to

62 provide new insight into ecosystem patterning is only beginning to be explored (Stroh and others

63 2001, Robinson and others 2008). Prior to this study the method had not been tested in an

64 environment with as extremely high soil water, salt, and clay contents as in salt marshes. To

65 further the applicability of EMI to salt marsh vegetation analysis, we developed a method to

66 filter out the effects of the soil clay content on the ECa data and leverage the information on

67 changes in soil saturation and salinity from sequential EMI surveys. Our approach was to

68 subtract the data from two EMI surveys (differential or time-lapse EMI; Lesch and others 2005,

69 Robinson and others 2009) and then convert the ECa difference values ( $\triangle \mathrm{ECa}$ ) to quantitative 
6727 Estimeates, of bs.oil water content and salinity change using Archie’s Law (Quantitative Differential

71 EMI, or Q-DEMI). Our Q-DEMI methodology quantified tidally-induced saturation and salinity

72 changes in the salt marsh root zone and enabled assessment of their spatial relationship to

73 vegetation zonation throughout a marsh in unprecedented detail.

74 To explore the second hypothesis, that each salt marsh plant species might bear a different

75 relationship to a suite of relevant variables, we sought to isolate distinguishing characteristics of

76 each of the major vegetation zones and individual species habitats composing the salt marsh

77 ecosystem. We used logistic regression modeling to assess the correlation between vegetation

78 patterns and the six geographic and edaphic metrics. The geophysical data on salt marsh edaphic

79 conditions provided greater insight into the underlying abiotic characteristics of the vegetation

80 patterns than was gained from the geographic metrics alone. In particular, spatial variability in

81 tidally-induced changes in soil water content and salinity, reflected in the Q-DEMI

$82 \Delta$ ECa metric, were the most effective means of distinguishing vegetation zones and habitats.

83 Multiple variables combine to support ecosystem structures, functions, habitat

84 heterogeneity, integrity, and supply of ecosystem services of salt marshes (Turner and Chapin

85 2005, Peterson and others 2008), but these variables are seldom analyzed in a spatially-

86 distributed manner. With this study we aimed to better understand how the effects of multiple

87 abiotic variables combine into something more than the sum of the parts, a spatially-variable

88 abiotic template upon which salt marsh vegetation patterns and biotic interactions are expressed.

89 A system-level perspective that integrates both abiotic and biotic variables may help inform the

90 maintenance and restoration of coastal wetlands, a matter of increasing interest worldwide amid

91 concerns of sea level rise, increased storm activity, and coastal development pressure (Peterson

92 and others 2008). 
Salt marsh spatial patterns and zonation

Moffett, Robinson, Gorelick

\section{MATERIALS AND METHODS}

$94 \quad$ Field Site and Hydrology Vegetation Mapping

The study site was a 0.9 ha intertidal salt marsh in southern San Francisco Bay, within the Palo Alto Baylands Nature Preserve ( $\left.37^{\circ} 27^{\prime} 54^{\prime \prime} \mathrm{N}, 122^{\circ} 6^{\prime} 58^{\prime \prime} \mathrm{W}\right)$. The geological and botanical history of the surrounding Santa Clara Valley were described by Cooper (1926) and the geology underlying the Palo Alto Baylands by Hamlin (1983). The history and character of the marsh were similar to that described by Hinde (1954) for the adjacent marsh to the south. The underlying site stratigraphy consisted of 3-5 meters of fine estuarine mud, predominantly montmorillonite clay, overlying a saline aquifer system (Hamlin 1983).

Plant species at the site were: Spartina foliosa, Salicornia virginica (S. depressa), Distichlis spicata, Jaumea carnosa, Grindelia stricta, Frankenia salina, Salsola soda, and Atriplex prostrata (see USDA (2009) for synonymous species names). The habitat occupied by each species was mapped by: marking the boundaries of assemblages distinguished by the presence/absence of each of the species, digitizing these polygonal boundaries using streaming GPS, and identifying the relative abundance of each species within each polygon. This method was similar to that of Zedler and others (1999) for San Diego Bay marshes, but with greater emphasis on identifying the locations of assemblage boundaries. Surveys of species' percent cover within $1-\mathrm{m}^{2}$ quadrats verified assemblage composition at 69 locations. The 57/134 assemblage polygons verified by one or more quadrats accounted for $81 \%$ of the marsh area. Vegetation zones were classified by the species of greatest (dominant) cover fraction in each assemblage polygon. The quadrat surveys confirmed that this was a sufficient means of identifying vegetation zones since assemblage composition within each zone defined in this 
Salt marsh spatial patterns and zonation

Moffett, Robinson, Gorelick

6\$67 Hianner2w,asbsonsistent. In addition to the spatial distribution of major vegetation zones, in this

117 study we were interested in the full range of conditions among which each plant species grew.

118 We refer to a plant species' habitat as all the areas the species occupied regardless of cover

119 density. In our vegetation discrimination analysis we assessed the salient characteristics of zones

120 and species habitats separately and compared the results.

121 Mapping Edaphic Conditions

122 A logical precursor to understanding salt marsh vegetation distribution is a three-

123 dimensional description of root zone edaphic conditions throughout the ecosystem, but obtaining

124 spatially-extensive data on relevant physical and chemical soil properties has been intractable

125 with point-sampling methods. The combination of heterogeneous soil water content, salinity, and

126 clay fraction was captured in this study by maps of bulk soil electrical conductivity (ECa). The

127 ECa data were obtained on two separate days by repeatedly traversing the field site carrying a

128 streaming EMI instrument (DUALEM-1S, Dualem, Inc., Milton, ON, Canada) and GPS, logged

129 concurrently. Sequential traverses were separated to account for the $\sim 4 \mathrm{~m}^{2}$ EMI measurement

130 support area. We estimated the vertical soil interval represented by the ECa data was 0-0.40 m

131 depth (see online supplement), approximately the depth of the salt marsh root zone. We post-

132 processed 5000 ECa measurements per survey (Robinson and others 2008) and corrected for

133 effects of soil temperature (Reedy and Scanlon 2003) to produce kriged ECa maps at 2-m

134 resolution. Successive measurements of ECa at test locations agreed to within $0.01 \mathrm{dS} / \mathrm{m}$, which

135 we take to be the ECa uncertainty, though the EMI instrument accuracy was $0.001 \mathrm{dS} / \mathrm{m}$.

136 The two EMI surveys were timed to capture different hydrologic conditions. The first

137 survey occurred just prior to the neap-spring tidal transition, when the marsh had not been

138 flooded in eight days (Nov. 19, 2007); we refer to these as data from “dry” marsh conditions. 
Salt marsh spatial patterns and zonation Moffett, Robinson, Gorelick

139 The second survey was partially into the next spring tide cycle, immediately following a flood 140 tide (Dec. 7); we refer to these as data from "wet” marsh conditions. We use the terms "dry" and 141 “wet” as qualitatively convenient reminders of antecedent tidal conditions although both 142 circumstances represent very moist soils (>80\% saturation). Both survey times were near mid143 day and no rain occurred while the marsh surface was exposed during the study period.

144 The field site experiences mixed semi-diurnal tides and a semi-arid Mediterranean

145 climate with winter precipitation $(\sim 39 \mathrm{~cm} / \mathrm{yr})$. The marsh plain is above mean high water and is 146 flooded by the higher high tide on $2 / 3-3 / 4$ of days during each spring-neap cycle. To verify

147 ambient hydrologic conditions, we monitored groundwater and tidal conditions at the site by 148 logging pressure and temperature every 10 minutes at the bed of the two primary tidal channels 149 and in 43 wells and piezometers installed 0.5 to $1.0 \mathrm{~m}$ into the marsh substrate. We monitored 150 hydraulic heads in the root zone with 23 tensiometer pairs spanning 10-15 and 20-25 cm depths. 151 Tensiometer data were collected manually during the geophysical surveys.

152 Empirical relationships have shown ECa to increase with increasing soil clay content, 153 water content $(\theta)$, or solution electrical conductivity (ECw) (e.g., Rhoades and others, 1999), 154 though not for as high values as occur in salt marshes. We conducted laboratory analyses to 155 establish the specific relationships between ECa and salt marsh soil properties. Twenty-three soil 156 sampling locations were strategically chosen using the ECa data from the first survey and 157 response-surface directed sampling (Corwin and Lesch 2005, Lesch 2005). After collecting ECa 158 data at each location, soil cores (2.5 cm diameter) were collected manually from $0-30 \mathrm{~cm}$ and 30 $15960 \mathrm{~cm}$ depth. The 0-30 cm depth interval was chosen to correspond roughly to the EMI signal 160 depth, enabling correlation with ECa survey data. The 30-60 cm deep samples were used in 161 parameterizing the Q-DEMI methodology, discussed below. The cores were immediately sealed 
Salt marsh spatial patterns and zonation

Moffett, Robinson, Gorelick

6227 Highlastía, bạs and promptly weighed in the laboratory. Samples were air-dried for 11-28 days,

163 homogenized subsamples weighed, oven-dried at $105^{\circ} \mathrm{C}$ for at least 12 hours and re-weighed,

164 and core water fractions and bulk densities calculated. Duplicate homogenized subsamples were

165 analyzed for soil paste extract electrical conductivity (ECe) and soil texture (University of Idaho

166 Pedology Laboratory standard procedures). Pore water samples extracted adjacent to the coring

167 locations from $30 \mathrm{~cm}$ depth using a suction lysimeter (“sipper”, $\leq 5 \mathrm{kPa}$ suction) were analyzed

168 in the laboratory for pore water electrical conductivity (ECw).

169 Quantitative Differential EMI Methodology

170 Each geophysical survey provided a snapshot of the combination of water, salt, and clay

171 conditions throughout the salt marsh at one point in time. We developed a method to transform

172 the difference in ECa between dry and wet tidal conditions into spatially-distributed, quantitative

173 estimates of changes in root zone soil water content and salinity. The premise of the Q-DEMI

174 method was that a change in the ECa value of a location was due to changing soil water content

175 and salinity while clay content remained constant. In our Q-DEMI analysis, we subtracted the

176 later “wet” ECa data from the earlier “dry” ECa data, simulating a case of increasing soil

177 moisture $\left(\Delta \mathrm{ECa}=\mathrm{ECa}_{\mathrm{dry}}-\mathrm{ECa}_{\mathrm{wet}}\right)$. We then determined the nature of the edaphic change,

178 whether caused by changing soil water content or by changing soil salinity, from the sign of

$179 \Delta \mathrm{ECa}$. An observed increase in ECa between dry and wet conditions (- $\triangle \mathrm{ECa})$ indicated an

180 increase in soil water content: an increase in salt content could not explain the change in these

181 areas because tidal waters were known a priori to be less saline $(33.4 \mathrm{dS} / \mathrm{m})$ than the marsh pore

182 waters $(\mathrm{ECw} \approx 57.2 \mathrm{dS} / \mathrm{m})$ to which they were added in order to wet-up the marsh. In contrast,

183 an observed decrease in ECa $(+\Delta \mathrm{ECa})$ indicated a decrease in pore water salinity: under

184 conditions of increasing tidal water availability, water content would remain constant or increase 
185 and so could not explain the ECa change in these areas. Because saturation and salinity changes

186 could occur simultaneously with opposing effects, the Q-DEMI calculations represent the

187 conservative case in which all ECa change is ascribed to the dominant process, identified by the 188 sign of $\triangle \mathrm{ECa}$.

189 Quantifying saturation and salinity changes was accomplished using Archie's Law in our 190 Q-DEMI methodology. Archie’s Law is a well-studied geophysical relationship between ECa 191 and: pore water conductivity (ECw), a formation factor (f) related to porosity, the soil saturation 192 (S), and the soil mineral surface conductivity due to adsorbed ionic charge $\left(\sigma_{\mathrm{s}}\right)$ (Kirsch 2006).

$193 \mathrm{ECa}=\mathrm{ECw} \cdot \mathrm{f} \cdot{ }^{2}+\sigma_{\mathrm{s}}$ $\mathrm{S}$

194 The mineral surface conductivity $\left(\sigma_{\mathrm{s}}\right)$ is important in soils with large clay fractions, such as in 195 our salt marsh, but has not been tabulated for salt marsh clay soils. We estimated f and $\sigma_{\mathrm{s}}$ using a 196 simple linear regression between ECa and pore water conductivity (ECw) for saturated samples 197 ( $\mathrm{S}=1)$. The samples used for this regression were from 30-60 cm depth since these samples were 198 known to be from the saturated zone below the water table. The resulting $\mathrm{f}$ and $\sigma_{\mathrm{s}}$ parameter 199 estimates compared favorably with estimates from more complicated methods (see online 200 supplement). These parameters permitted Q-DEMI calculation of changes in saturation, due to 201 aerated pore space being filled by tidal waters, and changes in salinity, due to flushing of salt 202 marsh soils, using variations on Archie’s Law.

203 In the saturation-change dominated (- $\Delta \mathrm{ECa})$ areas of the marsh we solved Archie's Law 204 (Eqn. 1) for the net soil water content change required to account for the observed increase in 205 ECa between dry and wet marsh conditions. To reduce one excess degree of freedom in the 206 calculation we assumed that initially aerated pore space in the soil was completely filled by the 207 flood tide, leading to a minimum estimate of soil saturation change since the effect of any 
BC287 Hagepedairzbould have reduced the magnitude of $\triangle \mathrm{ECa}$. The formula we derived to calculate 209 saturation change $(\Delta S)$ is shown below (Eqn. 2). The parameters are the: formation factor (f ), 210 mineral surface conductivity $\left(\sigma_{\mathrm{s}}\right)$, tidal flood water electrical conductivity (EC tide$_{\text {), and ECa }}$ 211 during wet $\left(\mathrm{ECa}_{\text {wet }}\right)$ and dry $\left(\mathrm{ECa}_{\mathrm{dry}}\right)$ conditions.

212

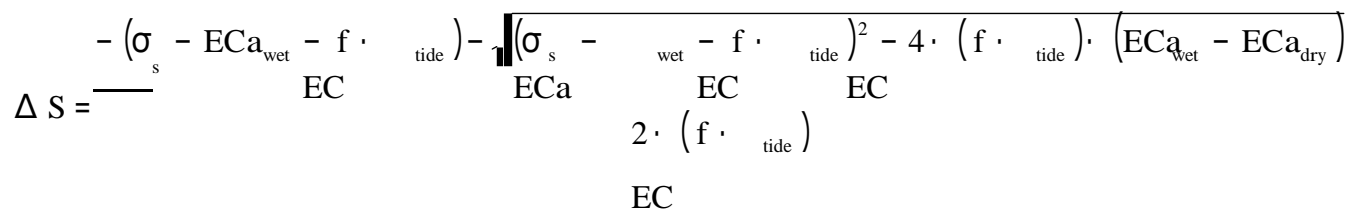

213 The real solution to Eqn. 2 using a positive discriminant root yielded unrealistic $\Delta$ S values

214 greater-than one, so was discarded.

215 In the salinity-change dominated $(+\Delta \mathrm{ECa})$ areas of the marsh we solved Archie’s Law

216 (Eqn. 1) for the pore water electrical conductivity (ECw) under dry and wet marsh conditions.

217 We then used the seawater equation of state to convert each ECW value to a salinity value.

218 Subtracting the salinity values yielded the change in salinity required to account for the observed

219 decrease in ECa between dry and wet marsh conditions. To reduce one excess degree of freedom

220 in the calculation we assumed that these areas of the marsh remained water-saturated, leading to

221 a minimum estimate of salinity change since the effect of any concurrent increase in soil water

222 content would have reduced the magnitude of $\Delta \mathrm{ECa}$. (Field observations suggested that these

223 areas of the marsh did remain saturated throughout dry and wet marsh conditions.)

224 In addition to the two maps of ECa, from dry and wet marsh conditions, the map of

225 saturation and salinity changes produced by the Q-DEMI methodology provided a third spatially-

226 distributed metric of salt marsh root zone characteristics against which to compare salt marsh

227 vegetation zonation.

228 Mapping Marsh Geometry

229 Geometric measures of spatial context within the ecosystem have traditionally been 230 employed as indicators of salt marsh ecosystem structure and spatially-variable intertidal 
Salt marsh spatial patterns and zonation Moffett, Robinson, Gorelick

231 hydrologic effects. The most common such geographic, or "landscape position" (Zedler and 232 others 1999), metrics are elevation and distance-to-channel. We mapped these metrics at the 233 same high resolution as our edaphic data sets. We represented marsh plain topography by a 2-m 234 horizontal resolution kriged map of 742 marsh plain surface elevations surveyed using a total 235 station, verified against LIDAR data. Major tidal channels are typically identified from aerial 236 imagery, but we could find no precedent for mapping the small, connected surficial drainage 237 pathways hidden under the vegetation canopy (“microtributaries”). We identified the banks of 238 major tidal channels and microtributaries by traversing them with a streaming GPS (20-cm post239 processed horizontal accuracy). Two distance-to-channel metrics were calculated as the shortest 240 straight-line distances from the center of each elevation grid cell to: 1) the nearest of the two 241 primary tidal channels (bounding and bisecting the study area, Figure 1); 2) the nearest channel 242 of any size.

243 Statistical Vegetation Differentiation

244 To contrast the utility of the six metrics described above in differentiating vegetation 245 zones and plant species habitats, we employed binary logistic regression (BLR) models (SPSS 246 2009). A logistic regression is analogous to a linear regression but with a categorical, instead of 247 continuous, dependent variable. By comparing the vegetation at each location in the marsh to the 248 collocated values of the six metrics and repeating this for all marsh locations, the BLR method 249 built models of those combinations of the six metrics that best distinguished the selected 250 vegetation zone or habitat type. BLR models were assessed at the 95\% confidence level. 251 We tested 108 BLR models, including univariate and multivariate analyses for each 252 vegetation zone and species habitat. In the univariate cases we assessed whether any of the six 253 metrics, alone, could correctly differentiate the marsh areas inside and outside each of the six 
B5247 Hiajpe vzegetmtion zones (6 metrics x 6 zones = 36 zone models). We also tested whether any of 255 the six metrics, alone, could correctly differentiate the marsh areas occupied or not occupied by 256 each species, regardless of its cover density (6 metrics x 6 species $=36$ habitat models). These 76 257 models served to test the univariate predictive capacity of each of the six metrics in relation to 258 vegetation patterning at our site. For these models, the two-fold null hypothesis in each case was 259 either $100 \%$ or $0 \%$ cover by the selected zone or species.

260 In the multivariate analyses, we built forward-conditional BLR models for each

261 vegetation zone and species habitat. This approach tested whether a combination of multiple 262 metrics could better identify the distinguishing characteristics of each zone and habitat than a 263 single metric. We tested three metric combinations: 1) the three geographic metrics, 2) the three 264 edaphic metrics, 3) all six metrics, for total of 36 multivariate models (3 combinations x (6 zones $265+6$ habitats $)=36$ models). The forward-conditional BLR method selected only those metrics 266 that significantly contributed to the zone or habitat prediction at the 95\% confidence level. For 267 these models, the two-fold null hypothesis in each case was either $100 \%$ or $0 \%$ cover by the 268 selected zone or species. The results of the BLR models revealed the key characteristics 269 distinguishing each habitat envelope and zone at our site.

270 RESULTS

271 Vegetation Patterns and Marsh Geometry

272 The spatial distribution of vegetation zones at the site is shown in Figure 1a, with zones

273 labeled by the genus of the dominant species. Quadrat surveys verified that species identified as 274 zone dominants occupied a majority ( $59 \% \pm 16 \%)$ of the zone’s cover. Zones dominated by the 275 succulent Salicornia (28\% of total marsh area) and the grasses Spartina (19\%) and Distichlis 276 (47\%) were most prominent at the site, with smaller areas dominated by Jaumea (4\%), 
277 Frankenia (1\%), and Grindelia (2\%). Salsola and Atriplex individuals were present in only a few

278 locations. The thick black outlines in Figure 1a highlight the three major vegetation zones,

279 dominated by Spartina, Distichlis, and Salicornia. Zone assemblage compositions are illustrated 280 by maps of relative cover density for each species (see appendix Figure A1), which were used to 281 assess the total habitat occupied by each species.

282 The elevation ranges ( $\mu \pm 1 \sigma \mathrm{m}$ above mean sea level) spanned by the species were not 283 distinct: Distichlis, $1.04 \pm 0.04$; Salicornia, $1.03 \pm 0.05$; Spartina, $1.00 \pm 0.06$; Jaumea, $1.03 \pm$ 284 0.05; Frankenia, $1.03 \pm 0.03$; Grindelia, $1.04 \pm 0.03$. Overlap between the elevation ranges of 285 key species is common in salt marshes despite their characteristically distinct vegetation zonation 286 (Silvestri and others 2005, Sadro and others 2007). The average marsh plain elevation from the 287 kriged topographic data was $1.02 \pm 0.06 \mathrm{~m}$ above mean sea level (m aMSL) and ranged from 2880.61 to $1.32 \mathrm{~m}$. The seeming visual correlation between areas of slightly lower elevation and the 289 southern, Spartina-dominated zone (Figure 1b) was not statistically supported because those 290 same elevations elsewhere in the marsh were dominated by different species. Employed in 291 univariate BLR models, elevation failed to justify rejecting the null hypothesis for any of the 292 vegetation zones or species habitats at our site.

294 major zones dominated by Spartina, Distichlis, and Salicornia to each occur at any distance from 295 the major tidal channels that bound and bisect the marsh (Figure 2a). The Spartina-dominated 296 zone appeared to coincide with a region of dense microtributaries (Figure 2b), yet neither

297 distance-to-channel metric warranted rejecting the univariate BLR models' null hypothesis for 298 any of the vegetation zones or species habitats.

299 Edaphic Conditions and Vegetation 
Salt marsh spatial patterns and zonation

Moffett, Robinson, Gorelick

Figure 26he2spatial structure of edaphic conditions throughout the marsh, and the magnitude of

301 ECa values reflecting these conditions, remained consistent between the dry (Figure 3a) and wet

302 (Figure 3b) surveys. Mean ECa values for the two surveys were 13.37 and $13.71 \mathrm{dS} / \mathrm{m}$,

303 respectively ( $2.05 \mathrm{dS} / \mathrm{m}$ standard deviations; correlation coefficient $\mathrm{r}=0.83$ ). Tensiometer data

304 confirmed that the root zone was drier during the first, “dry” geophysical survey than during the

305 second, "wet” survey. Tides rapidly and uniformly covered the marsh to a depth of $0.5 \mathrm{~m}$ during

306 spring tide flooding events between the surveys. The specific relationships between ECa values

307 and edaphic conditions (soil solution and paste extract conductivities and water and clay

308 contents) determined for this salt marsh are presented in the appendix.

309 The configuration of vegetation zones (Figure 1a) did not resemble the spatial pattern of

310 edaphic conditions (Figure 3). Instead, interior marsh areas that exhibited persistent high soil

311 water content and/or salinity (high ECa) appeared coincident with major zone boundaries. A

312 phenomenon of stressful edaphic conditions and major zone boundaries occurring in the same

313 location was described for Spartina and Salicornia in northern San Francisco Bay salt marshes

314 by Mahall and Park (1976a) but had not been illustrated in two dimensions; our result is

315 consistent with this explanation of ecotone locations. Though not consistently correlated with

316 any vegetation zone or elevation, the edaphic variability in the marsh was significantly related to

317 the hydrologic processes represented by the distance-to-channel metrics ( $r=0.36$ to 0.54 ). Low

318 soil saturation and/or salinity (low ECa) occurred close to tidal channels and more stressful

319 edaphic conditions (high ECa) occurred further from the channels. Neither ECa data set provided

320 information sufficient to reject the null hypothesis of the univariate BLR models.

321 The spatial pattern of tidally-induced changes in edaphic conditions revealed by

322 subtracting the wet and dry ECa surveys ( $\triangle \mathrm{EC}$, Figure $4 \mathrm{a}$ ) was more heterogeneous than the 
323 spatial variability in static edaphic conditions (Figure 3). The pattern of change was not altered

324 by the Q-DEMI calculations, which converted $\triangle \mathrm{ECa}$ values to soil saturation and salinity change

325 quantities (Figure 4b). The conversion was made using values of $\mathrm{f}=0.223$ and $\sigma_{\mathrm{s}}=2.479 \mathrm{dS} / \mathrm{m}$.

326 The average estimated saturation change in the fluid-exchange dominated areas of the marsh

327 (blue in Figure $4 \mathrm{~b})$ was $6.2 \pm 5.5 \%(\mu \pm 1 \sigma)$. The average estimated salt loss from the salt-

328 exchange dominated areas of the marsh (red in Figure $4 \mathrm{~b}$ ) was $0.77 \pm 0.64 \mathrm{~kg} / \mathrm{m}^{2}$. The large

329 standard deviations of these average results were due to highly heterogeneous soil aeration and

330 flushing throughout the marsh. Despite the Q-DEMI methodology producing conservative

331 estimates of the magnitude of edaphic change, we emphasize that the methodology permits

332 mapping the magnitude of salt and water exchange in a spatially-distributed way throughout an

333 ecosystem for the first time.

334 Spatial patterns of saturation and salinity change did not qualitatively resemble

335 vegetation zonation (Figures 1a, 4b), yet BLR models based on $\triangle \mathrm{ECa}$ were able to partially

336 describe the zones dominated by every species except Distichlis. For the Salicornia-, Spartina-,

337 Jaumea-, Frankenia-, and Grindelia-dominated zones, the BLR models correctly distinguished

$338 \quad 22-44 \%$ of the area inside each zone and 63-67\% of the area outside each zone. Though short of

339 the ideal prediction (100\% correct both inside and outside each zone), these results using the

$340 \Delta$ ECa metric were a substantial improvement over the null hypothesis returned by the models

341 based on the other five metrics.

$342 \Delta$ ECa BLR models were more successful at distinguishing between marsh areas occupied

343 and not occupied by each of the six plant species, regardless of cover density (appendix Figure

344 A1). $\triangle \mathrm{ECa}$ BLR habitat models correctly identified $64 \%$ of the observed Distichlis and

345 Salicornia occurrences and $37 \%$ and $44 \%$ of observed absences, respectively. $\triangle \mathrm{ECa}$ BLR 
Salt marsh spatial patterns and zonation

Moffett, Robinson, Gorelick

6467 Figdels 2for,24partina and Jaumea habitat correctly predicted 70\% and 73\% of the observed

347 occurrences and $41 \%$ and $46 \%$ of observed absences, respectively. $\triangle E C a$ BLR models for

348 Frankenia and Grindelia were less successful at correctly predicting occurrences of these species

349 (28\% and 23\%, respectively) but more successful at correctly predicting absences (63\% and

$35060 \%$, respectively). For all six species, the $\triangle \mathrm{ECa} B L \mathrm{R}$ habitat models justified rejecting the null

351 hypotheses (95\% confidence).

352 The patterns in edaphic conditions and geographic metrics of salt marsh structure support

353 our two hypotheses regarding the spatial nature of zonation-relevant variables and their

354 relationship to salt marsh vegetation distribution. 1) Multiple metrics relevant to salt marsh

355 vegetation zonation each exhibit different patterns. These patterns are characterized by different

356 spatial scales and degrees of spatial heterogeneity. 2) Alone, only the $\Delta \mathrm{ECa}$ metric provided

357 information useful in indentifying vegetation zones and species habitats. The relation of the

$358 \Delta$ ECa metric to vegetation differed depending on the species considered and whether the species

359 was considered alone or as a zone-dominant.

360 Multivariate Vegetation Zone and Habitat Discrimination

361 We hypothesized that a combination of multiple metrics might better discriminate salt

362 marsh vegetation zones and individual species habitats than univariate models. The metric

363 combinations we tested using forward-conditional BLR models were: 1) the three geographic

364 metrics, 2) the three edaphic metrics, and 3) all six metrics. Salient results are presented here;

365 complete BLR model results are provided in the online supplement.

366 Except in the case of the Distichlis-dominated zone, none of the multivariate models

367 identified vegetation zones or habitats significantly better than the univariate $\triangle \mathrm{ECa} B L \mathrm{R}$ models.

368 For the Distichlis-dominated zone, a BLR model including all three geographic metrics correctly 
Salt marsh spatial patterns and zonation

Moffett, Robinson, Gorelick

369 predicted $45 \%$ of the marsh area within the zone and $72 \%$ of the area outside the zone, compared

370 to the null hypothesis returned by the univariate $\triangle \mathrm{ECa}$ BLR model. This result suggests that

371 Distichlis may be reliant on the hydrologic marsh processes implicit in the elevation and

372 distance-to-channel metrics to maintain a dominant cover fraction. In contrast, the dominance of

373 the other five major species at the site may be related to the magnitude of temporal variation in

374 root zone soil water content and soil salinity, represented by the $\Delta \mathrm{ECa}$ metric. For example,

$375 \Delta$ ECa was the only significant predictor of the marsh areas that Jaumea occupied, whether it was

376 the dominant cover fraction or not, even when the other five metrics were made available to the

377 forward-conditional model. However, a BLR model based on $\triangle$ ECa correctly predicted $73 \%$ of

378 Jaumea occurrences in the salt marsh but only 32\% of Jaumea-dominated zones. The difference

379 between the zone and habitat models suggest that the tidally-induced changes in root zone water

380 and salt content represented by the $\Delta \mathrm{ECa}$ metric may affect the growth and interspecific

381 interactions of a species within a vegetation assemblage differently than the growth and survival

382 of individual plants of that species throughout the marsh.

383 DISCUSSION

384 Vegetation Zonation

385 Our use of geophysical EMI technology was motivated by the inherent spatial limitations

386 of transect- and plot-based methods of investigating in situ salt marsh vegetation patterning.

387 Logistic regression models based on extensive two-dimensional data identified major

388 characteristics that distinguished the vegetation zones and species habitats at our site. The detail

389 of our regression models, based on over 2000 data points, makes it striking that some zones and

390 species habitats were uniquely identified by a combination of multiple variables (e.g., Distichlis)

391 but others were best identified by a single variable (e.g., Jaumea). It is also significant that there 
Salt marsh spatial patterns and zonation

Moffett, Robinson, Gorelick

6227 magsie largedifference in the ability of the models to describe the key characteristics of the total

393 habitat envelope of a species versus the zone for which it provided the dominant cover class.

394 Existing theory suggests that the survival of individual salt marsh plants may be strongly affected

395 by environmental conditions but that the growth rate and relative cover of a species may be more

396 strongly affected by interspecific interactions with its neighbors (e.g., Emery and others, 2001).

397 This hypothesis seems to be supported by the greater success with which our regression models,

398 based on metrics of abiotic ecosystem variability, were able to identify characteristic individual

399 species habitats compared to vegetation zones.

400 Tide-induced Edaphic Change

401 The most striking result of the vegetation discrimination analysis was the utility of the

$402 \Delta$ ECa metric, alone, in identifying vegetation zones and species habitats. The Q-DEMI method

403 and soil core analyses showed that $\Delta \mathrm{ECa}$ represented the amount of water and salt exchanged

404 from the root zone (Figure 4b) between two points in time. The data from this study could not

405 definitively separate, however, whether observed changes in edaphic conditions were due

406 entirely to intervening tidal flooding, or due to a combination of physical and biological effects.

407 The lack of correlation between $\triangle \mathrm{ECa}$ and either elevation or distance-to-channel argues against

408 the hydrologic processes implied by the elevation and distance-to-channel metrics as the

409 dominant determinants of spatial patterns in edaphic change.

410 The phenomenon of large, broadly distributed decreases in soil salinity, identified in this

411 study by decreases in ECa between dry and wet marsh conditions, has not previously been

412 reported and the precise cause is unknown. Potential mechanisms for what was apparently rapid

413 flood tide-induced salt removal from the salt marsh root zone include: diffusion, leaching, or

414 dissolution of salt from the surface; plant salt uptake; or dilution by convective mixing in soil 
415 macropores. On average, the $0.77 \mathrm{~kg} / \mathrm{m}^{2}$ of salt loss from the salt-exchange dominated areas of 416 the marsh constituted approximately 15\% of the salt contained in the root zone pore water fluids.

417 Were dilution the only mechanism in operation, a salinity decrease of this magnitude would have 418 required approximately $70 \%$ of the root zone pore water to be replaced by the less salty tidal 419 waters, on average across the marsh. Salt uptake by vegetation would reduce the amount of pore 420 water turn-over required to match the geophysical observations.

\section{Plant - Soil Interactions}

422 Qualitative comparison of tide-induced edaphic change and vegetation zonation (Figures 423 1a, 4b) suggests that the greatest density of areas experiencing large saturation increases due to 424 tidal flooding occurred in the Spartina-dominated zone, the greatest density of areas 425 experiencing salt loss occurred in the Salicornia-dominated zone, and changes of intermediate 426 magnitude prevailed in the Distichlis-dominated zone. We hypothesize that these spatial 427 coincidences may be related to three different ecosystem engineering effects enabled by the 428 different physiologies and morphologies of these three species.

429 First, enhanced sediment deposition within, and enhanced erosion around, Spartina 430 clusters has been reported at low marsh elevations (Temmerman and others 2007, van Hulzen 431 and others 2007). This mechanism may also explain the great density of microtributaries in the 432 Spartina-dominated zone (Figure 2) at our high-elevation marsh site. Because Spartina is more 433 productive in low-salinity conditions than Salicornia and Distichlis (Bertness and others 1992, 434 Mahall and Park 1976b), it may remain dominant precisely where surrounding microtributaries 435 enhance pore water drainage and flushing. This hypothesis is supported by experimental 436 manipulations of marsh hydrology (Balling and Resh 1983, Wiegert and others 1983). 
Salt marsh spatial patterns and zonation

Moffett, Robinson, Gorelick

\$277 Figure Sxęcond, Salicornia is one of the most salt-tolerant halophytes, producing more biomass

438 than Spartina and Distichlis at high salinities and water contents, but less at low salinities

439 (Pearcy and Ustin 1984). We hypothesize that efficient root salt exclusion and water use by

440 Salicornia (Mahall and Park 1976b) may locally maintain a saturated and salty root zone,

441 enhancing Salicornia competitiveness.

442 Third, the matted morphology of Distichlis may decrease surface water velocities and so

443 inhibit erosion of microtributaries (and so Spartina-dominance) in areas of low salinity favorable

444 for both grasses (Bertness and others 1992). Distichlis, like Salicornia, is quite effective at

445 excluding ions at the root membrane (Marcum and others 2007), and so may persist in areas of

446 intermediate salinity, where it is often found nearly co-dominant with Salicornia at our site. A

447 lack of known disturbance at our study site in at least 30 years argues against disturbance as an

448 explanation for the distribution of Distichlis at the site; furthermore, both Distichlis and

449 Salicornia are very effective at recovering from disturbance in northern California salt marshes,

450 neither necessarily competitively displacing the other (Allison, 1995).

451 CONCLUSION

452 This study explored the spatial relationships between salt marsh vegetation patterns and

453 six zonation-related metrics. The metrics were based on geographic and edaphic data: elevation,

454 distance to major tidal channels and to the nearest channel of any size, the soil saturation/salinity

455 state during dry and wet marsh conditions, and the difference in this edaphic state between

456 conditions. The metrics, mapped at high resolution throughout a salt marsh ecosystem, exhibited

457 very different spatial patterns. Among the six metrics, information on tide-induced edaphic

458 change was most useful in discriminating salt marsh vegetation zones and individual species

459 habitats. Unexpectedly poor spatial correlation between edaphic conditions and proxies for 
Salt marsh spatial patterns and zonation Moffett, Robinson, Gorelick

460 hydrologic forcing suggest, instead, the potential importance of plant-soil relations in spatial 461 patterns of tide-induced edaphic change.

462 The results of this study supported two hypotheses relating the spatial patterns of salt 463 marsh vegetation and abiotic variables. The hypotheses extend classic concepts of niche breadth 464 and overlap (Colwell and Futuyma 1971) into three spatial dimensions. First, the influence of 465 each resource used by, and stressor endured by, salt marsh vegetation may be spatially variable. 466 These spatial patterns are combined implicitly in nature by superposition and may exhibit 467 emergent patterns and properties that are more than the sum of the contributing variables. 468 Second, multiple contributing variables may affect the distribution of interacting species 469 assemblages differently than the distribution of individuals. Multivariate relationships between 470 abiotic and biotic ecosystem patterns are difficult to assess without high-resolution spatially471 distributed data at the ecosystem-scale. Geophysical methods such as EMI and Q-DEMI provide 472 means to obtain high-resolution, spatially-distributed data on root zone soil properties that have 473 previously been prohibitively difficult to obtain. In this study, such edaphic data was more useful 474 in characterizing salt marsh vegetation zones and habitats than traditional geographic metrics 475 such as elevation and distance-to-channel.

476 The challenge of predicting the vegetation distribution of intertidal salt marsh ecosystems 477 persists. Despite functional similarity between different salt marsh species around the world, 478 regional and latitudinal differences so far prohibit development of a universally-applicable, 479 mechanistic, zonation model (Farina and others, 2009; Pennings and others 2003). Even if such a 480 model were possible, its accuracy would necessarily vary from site to site. Some of the most 481 pressing questions regarding salt marsh vegetation zonation, such as the expected response of a 482 marsh to restoration efforts or to an invasive species, must be answered on a site-by-site basis 
Salt marsh spatial patterns and zonation

Moffett, Robinson, Gorelick

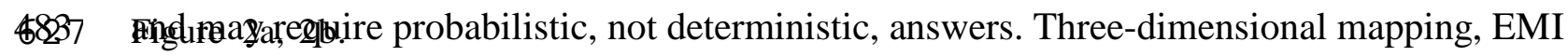

484 geophysics, and the Q-DEMI methodology can provide a cost-effective, rapid, and repeatable

485 means to statistically characterize a salt marsh site. The resulting spatial and temporal patterns

486 can then be used as a foundation upon which to interpret or predict vegetation distributions and

487 biotic interactions based on existing region- and species-specific knowledge. Linking plot-scale

488 studies of plant-soil relations and interspecific interactions to marsh-scale studies of spatial

489 variability such as this one may provide the most promising means to fill the gap between the

490 general principles and site-specific needs of salt marsh vegetation zonation science.

\section{ACKLOWLEDGMENTS}

492 This work was supported by National Science Foundation grant EAR-0634709 to Stanford

493 University. Any opinions, findings, and conclusions or recommendations expressed in this

494 material are those of the authors and do not necessarily reflect the views of the National Science

495 Foundation. We thank the City of Palo Alto Baylands Nature Preserve and K. Brauman, M.

496 Cardiff, S. Giddings, E. Hult, K. Knee, I. Lebron, and K. Tufano for field assistance.

497 LITERATURE CITED

498 Allison SK. 1995. Recovery from small-scale anthropogenic disturbances by northern California

499 salt marsh plant assemblages. Ecological Applications 5(3): 693-702.

500 Balling SS, Resh VH. 1983. The influence of mosquito-control recirculation ditches on plant

501 biomass, production and composition in two San Francisco Bay salt marshes. Estuarine Coastal

502 and Shelf Science 16: 151-161.

503 Bertness MD, Gough L, Shumway SW. 1992. Salt tolerances and the distribution of fugitive salt

504 marsh plants. Ecology 73: 1842-1851. 
Salt marsh spatial patterns and zonation

505 Colwell RK, Futuyma DJ. 1971. On the measurement of niche breadth and overlap. Ecology 506 52(4): 567-576.

507 Cooper WS. 1926. Vegetational development upon alluvial fans in the vicinity of Palo Alto, 508 California. Ecology 6: 325-473.

509 Corwin DL, Lesch SM. 2005. Applications of apparent soil electrical conductivity in precision 510 agriculture. Computers and Electronics in Agriculture 46: 103-133.

511 Emery NC, Ewanchuk PJ, Bertness MD. 2001. Competition and salt-marsh plant zonation: stress 512 tolerators may be dominant competitors. Ecology 82: 2471-2485.

513 Farina JM, Silliman BR, Bertness MD. 2009. Can conservation biologists rely on established 514 community structure rules to manage novel systems? ... Not in salt marshes. Ecological 515 Applications 19(2): 413-422.

516 Friedman S P. 2005. Soil properties influencing apparent electrical conductivity: a review.

517 Computers and Electronics in Agriculture 46: 45-47.

518 Hamlin SN. 1983: Injection of treated wastewater for ground-water recharge in the Palo Alto 519 Baylands, California: Hydraulic and chemical interactions -- preliminary report. U.S. 520 Geological Survey Water-Resources Investigation Report 82-4121.

521 Hinde HP. 1954. The vertical distribution of salt marsh phanerogams in relation to tide levels.

522 Ecological Monographs 24: 209-225.

523 Kirsch R. 2006. Petrophysical properties of permeable and low-permeable rocks. Kirsch R, 524 editor. Groundwater Geophysics. New York: Springer.

525 Lesch SM. 2005. Sensor directed response surface sampling designs for characterizing variation 526 in soil properties. Computers and Electronics in Agriculture 46: 153-179. 
Salt marsh spatial patterns and zonation

Moffett, Robinson, Gorelick

6227 Mathatl Ra,2Bark RB. 1976a. The ecotone between Spartina foliosa trin. and Salicornia virginica

528 l. in salt marshes of northern San Francisco Bay: I. biomass and production. Journal of Ecology

$529 \quad$ 64: 421-433.

530 Mahall BE, Park RB. 1976b. The ecotone between Spartina foliosa trin. and Salicornia virginica

531 l. in salt marshes of northern San Francisco Bay: II. soil water and salinity. Journal of Ecology

$532 \quad 64: 793-809$.

533 Marani M, Silvestri S, Belluco E, Ursino N, Comerlati A, Tosatto O, Putti M. 2006. Spatial

534 organization and ecohydrological interactions in oxygen-limited vegetation ecosystems. Water

535 Resources Research 42: W06D06.

536 Marcum KB, Yensen NP, Leake JE. 2007. Genotypic variation in salinity tolerance of Distichlis

537 spicata turf ecotypes. Australian Journal of Experimental Agriculture 47: 1506-11.

538 Pearcy RW, Ustin SL. 1984. Effects of salinity on growth and photosynthesis of three California

539 tidal marsh species. Oecologia 62: 68-73.

540 Pennings SC, Callaway RM. 1992. Salt marsh plant zonation: the relative importance of

541 competition and physical factors. Ecology 73: 681-690.

542 Pennings SC, Grant M-B, Bertness MD. 2005. Plant zonation in low-latitude salt marshes:

543 disentangling the roles of flooding, salinity and competition. Journal of Ecology 93: 159-167.

544 Pennings SC, Selig ER, Houser LT, Bertness MD. 2003. Geographic variation in positive and

545 negative interactions among salt marsh plants. Ecology 84(6): 1527-1538.

546 Peterson CH, Able KW, DeJong CF, Piehler MF, Simenstad CA, Zedler JB. 2008. Practical

547 proxies for tidal marsh ecosystem services: application to injury and restoration. Advances in

$548 \quad$ Marine Biology 54: 221-266. 
Salt marsh spatial patterns and zonation

549 Reedy RC, Scanlon BR. 2003. Soil water content monitoring using electromagnetic induction.

$550 \quad$ Journal of Geotechnical Geoenvironmental Engineering 129: 1028-1039.

551 Rhoades JD, Chanduvi F, Lesch S. 1999. Soil salinity assessment: methods and interpretation of 552 electrical conductivity measurements. Irrigation and Drainage Paper 57, FAO, Rome, Italy.

553 Robinson DA, Abdu H, Jones SB, Seyfried M, Lebron I, Knight R. 2008. Eco-geophysical

554 imaging of watershed-scale soil patterns links with plant community spatial patterns. Vadose

$555 \quad$ Zone Journal 7(4): 1132-1138.

556 Robinson DA, Lebron I, Kocar B, Phan K, Sampson M, Crook N, Fendorf F. 2009. Time-lapse 557 geophysical imaging of soil moisture dynamics in tropical deltaic soils: an aid to interpreting

558 hydrological and geochemical processes. Water Resources Research 45: W00D32.

559 Sadro S, Gastil-Buhl M, Melack J. 2007. Characterizing patterns of plant distribution in a 560 southern California salt marsh using remotely sensed topographic and hyperspectral data and 561 local tidal fluctuations. Remote Sensing of the Environment 110: 226-239.

562 Sanderson EW, Foin TC, Ustin SL. 2001. A simple empirical model of salt marsh plant spatial 563 distributions with respect to a tidal channel network. Ecological Modeling 139: 293-307.

564 Silvestri S, Defina A, Marani M. 2005. Tidal regime, salinity and salt marsh plant zonation.

565 Estuarine Coastal and Shelf Science 62: 119-130.

566 SPSS. 2009. PASW Statistics 17. Chicago, IL: SPSS Inc.

567 Stroh JC, Archer S, Doolittle JA, Wilding L. 2001. Detection of edaphic discontinuities with 568 ground-penetrating radar and electromagnetic induction. Landscape Ecology 16: 377-390.

569 Temmerman S, Bouma TJ, van de Koppel J, van der Wal D, De Vries MB, Herman PMJ. 2007. 570 Vegetation causes channel erosion in a tidal landscape. Geology 35: 631-634. 
Salt marsh spatial patterns and zonation

Moffett, Robinson, Gorelick

67217 Tidner M,GbChapin FS III. 2005. Causes and consequences of spatial heterogeneity in ecosystem

572 function. Lovett GM, Jones CG, Turner MG, Weathers KC, editors. Ecosystem Function in

573 Heterogeneous Landscapes. New York: Springer.

574 USDA. 2009. Plants Database. U.S. Department of Agriculture, Natural Resources Conservation

575 Service. <http://plants.usda.gov/index.html>

576 USFW. 2008. Species Account: California Clapper Rail. Species Account: Salt Marsh Harvest

577 Mouse. U.S. Fish and Wildlife Service, Sacramento Office.

$578<$ http://www.fws.gov/sacramento/es/animal_spp_acct/>>

579 van Hulzen JB, van Soelen J, Bouma TJ. 2007. Morphological variation and habitat modification

580 are strongly correlated for the autogenic ecosystem engineer Spartina anglica (common

581 cordgrass). Estuaries and Coasts 30: 3-11.

582 Wiegert RG, Chalmers AG, Randerson PF. 1983. Productivity gradients in salt marshes: the

583 response of Spartina alterniflora to experimentally manipulated soil water movement. Oikos

584 41(1): 1-6.

585 Zedler JB, Callaway JC, Desmond JS, Vivian-Smith G, Williams GD, Sullivan G, Brewster AE, 586 Bradshaw BK. 1999. Californian salt-marsh vegetation: an improved model of spatial pattern.

$587 \quad$ Ecosystems 2: 19-35.

588 APPENDIX

589 Vegetation Habitat Distribution Maps

590 (Figure A1 and caption.)

591 Relating ECa to Salt Marsh Soil Properties

592 Despite the extreme environment, correlations between our ECa and soil core data

593 showed that salt marsh ECa measurements can be interpreted in terms of three key edaphic 
594 properties: water content, salt content, and clay content. Variability in ECa values was 595 significantly related to variability in each of these edaphic properties ( $\mathrm{p}<0.005$, Table A1). At 596 our site the EMI signal was dominated by the total salt content of the soil (as measured by the 597 soil paste extract conductivity, ECe) but the soil water $(\theta)$ and clay contents also contributed. The 598 clay content throughout the marsh was remarkably uniform and so did not figure significantly in 599 our analysis. See the online supplement for comparison of our salt marsh relationships with prior 600 published relationships at lower water, salt, or clay contents. In brief, we conclude that the salt 601 marsh ECa - ECe and ECa - $\theta$ relationships scale as in other environments but that the soil pore 602 solution conductivity (ECw) and soil clay content of intertidal salt marshes have unique effects 603 on EMI signals. 
Salt marsh spatial patterns and zonation

Moffett, Robinson, Gorelick

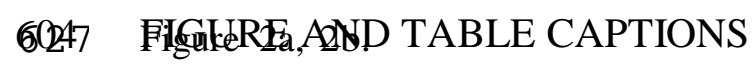

605 Figure 1. a) Major vegetation zones, classified by the species of greatest cover fraction. b) Site

606

607

608 topography, units: meters above mean sea level.

Figure 2. a) Shortest distance to one of the main tidal channels, shown in light blue bounding and bisecting the marsh site. b) Shortest distance to the nearest channel of any size, 609 including microtributaries shown in dark blue.

610 Figure 3. Root zone bulk soil electrical conductivity (ECa) from (a) dry and (b) wet marsh 611

612 conditions. Dark blue lines are channel and microtributary banks, black lines depict major vegetation zone boundaries.

Figure 4. a) Edaphic change between dry and wet marsh conditions, represented by the change in bulk soil electrical conductivity ( $\triangle \mathrm{ECa}, \mathrm{dS} / \mathrm{m}$ ). b) Result of Q-DEMI conversion of $\Delta$ ECa to changes in root zone saturation $(\%)$ or salinity $\left(\mathrm{kg} / \mathrm{m}^{3}\right)$ between dry and wet marsh conditions. Blue areas were dominated by net saturation increase between dry and wet conditions, red areas were dominated by net salinity decrease. Dark blue lines

620 Figure A1. Relative cover fraction of each major plant species at the site: primary cover, are channel and microtributary banks, black lines depict major vegetation zone boundaries. secondary cover, tertiary cover, present as minor cover. Clockwise from lower left: Distichlis spicata, Salicornia virginica (S. depressa), Spartina foliosa, Grindelia stricta, Frankenia salina, Jaumea carnosa.

Table A1. Relation of ECa data to soil properties. 
Salt marsh spatial patterns and zonation

\section{FIGURES}

626 Figure la, lb.

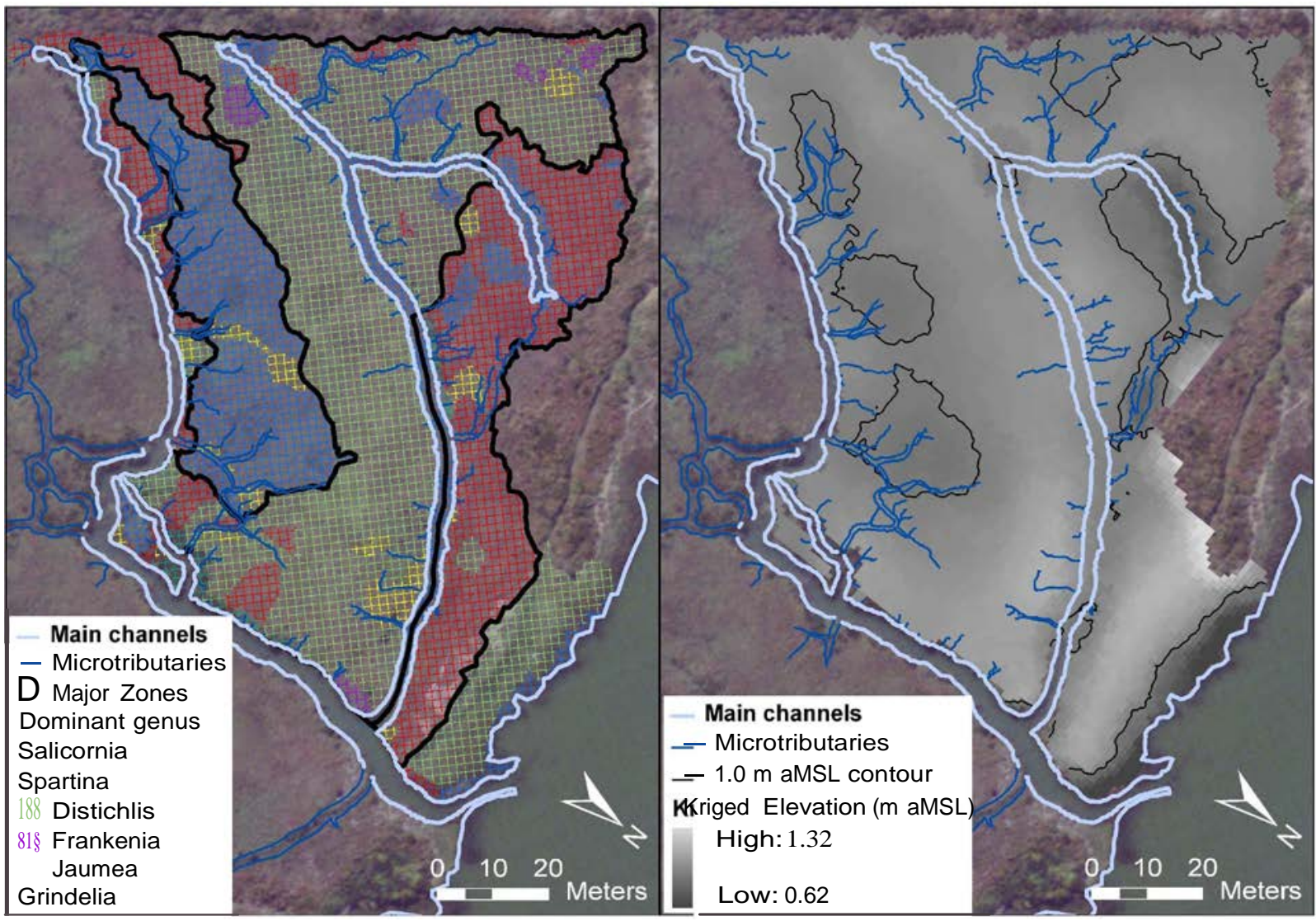


627 Figure 2a, 2b.

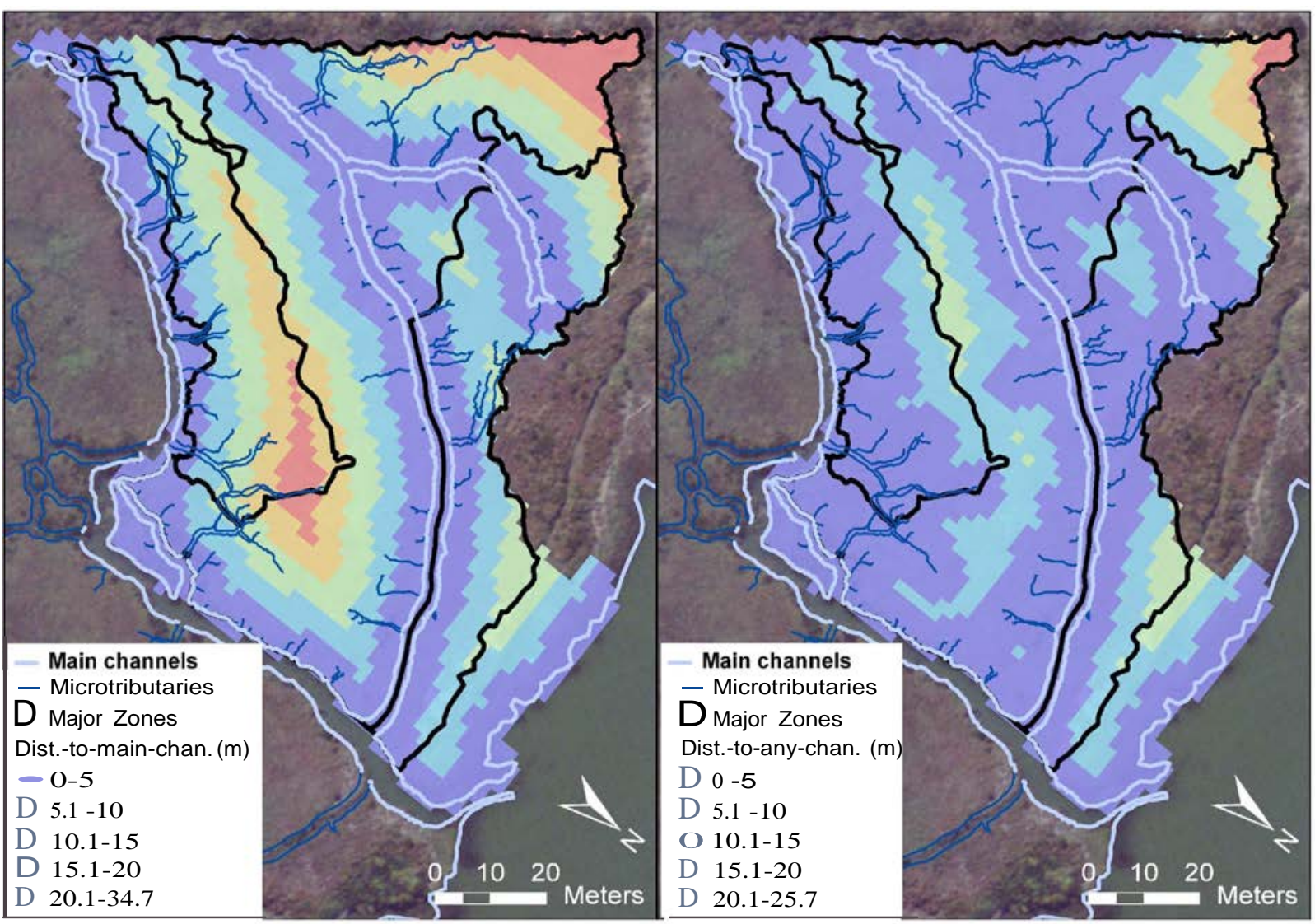


628 Figure 3a, 3b.

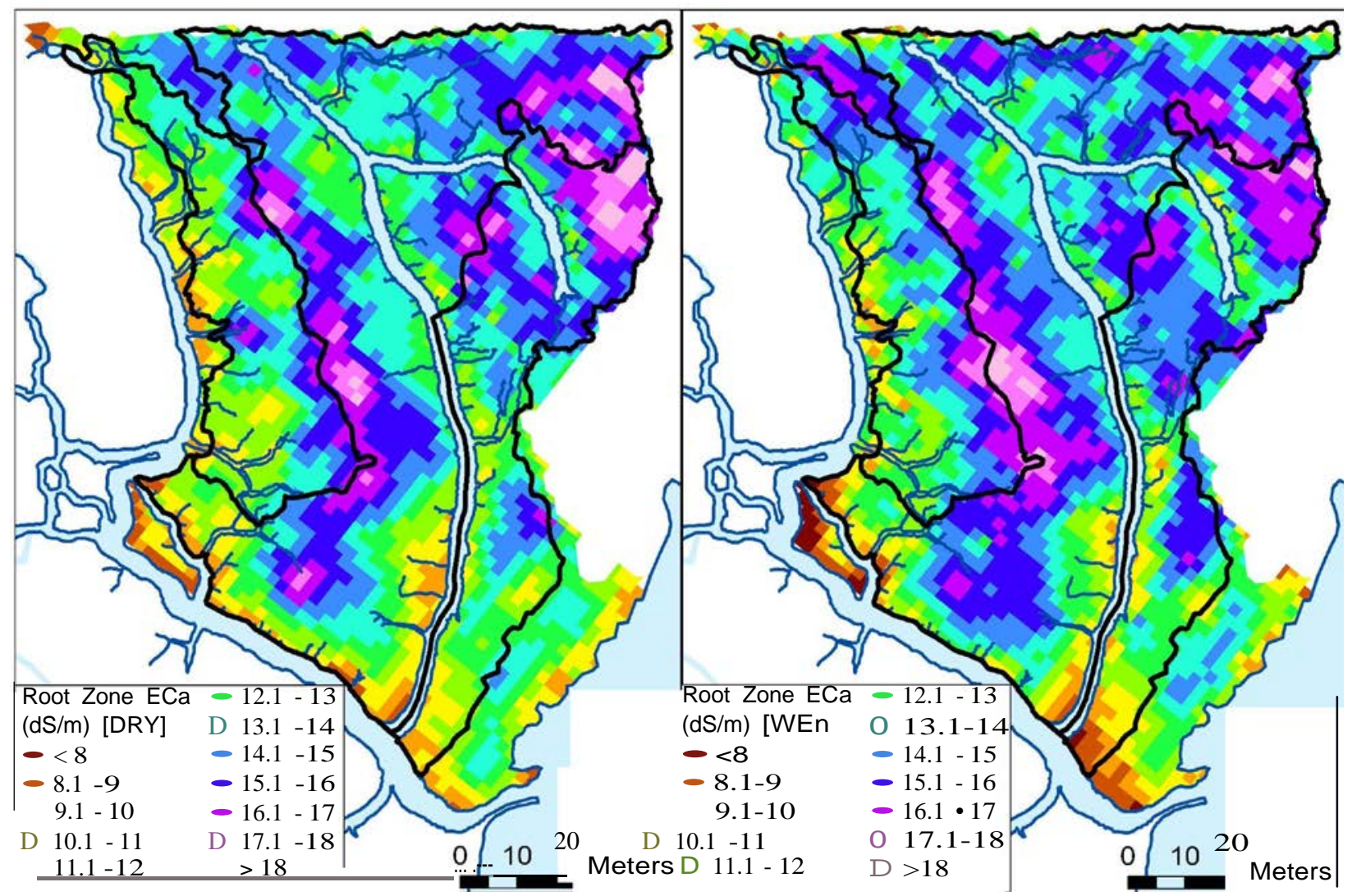


629 Figure 4a, 4b.

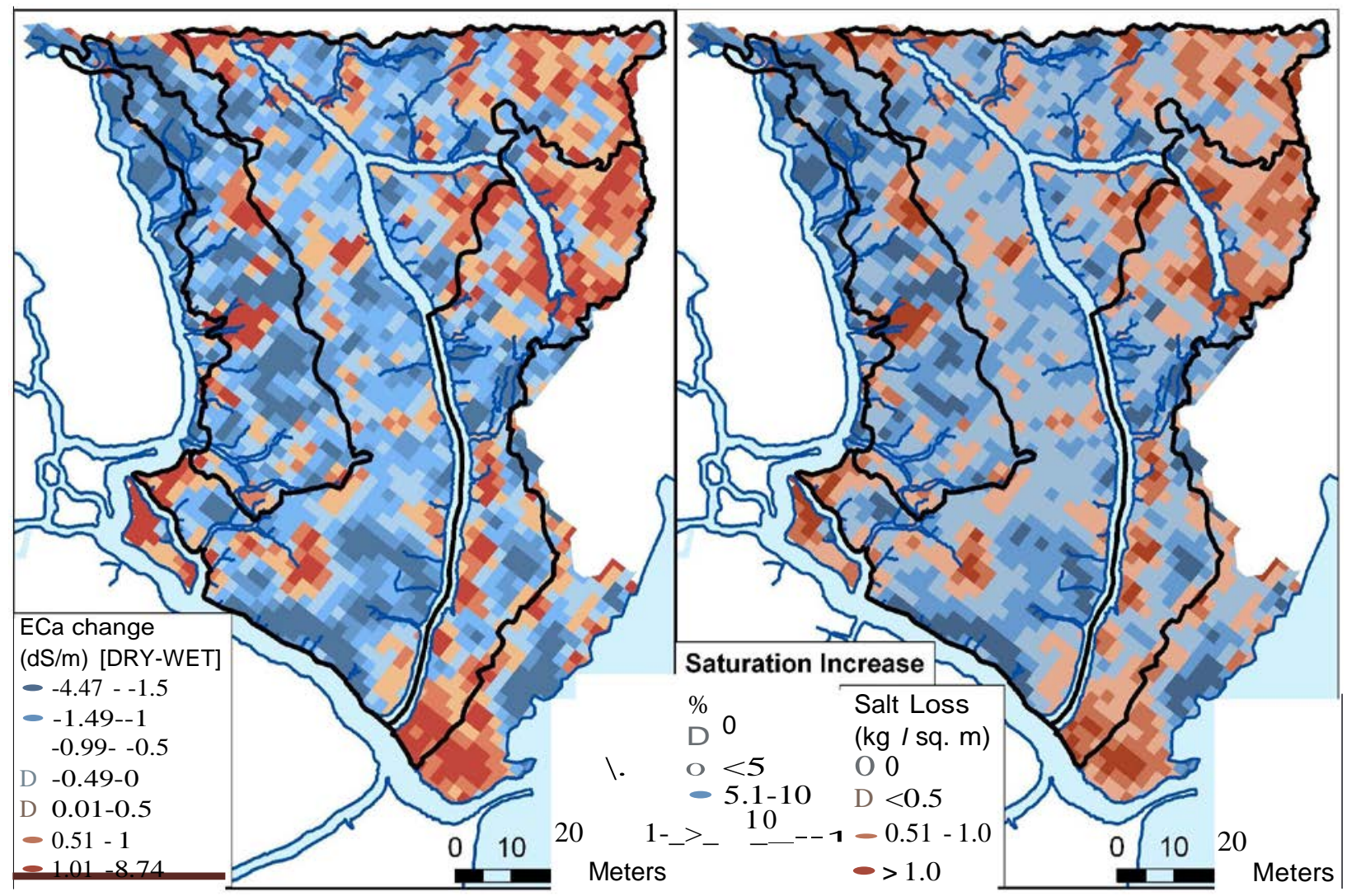




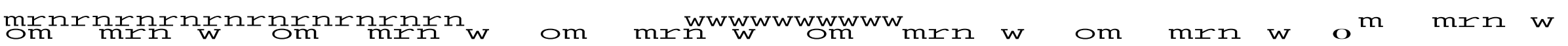

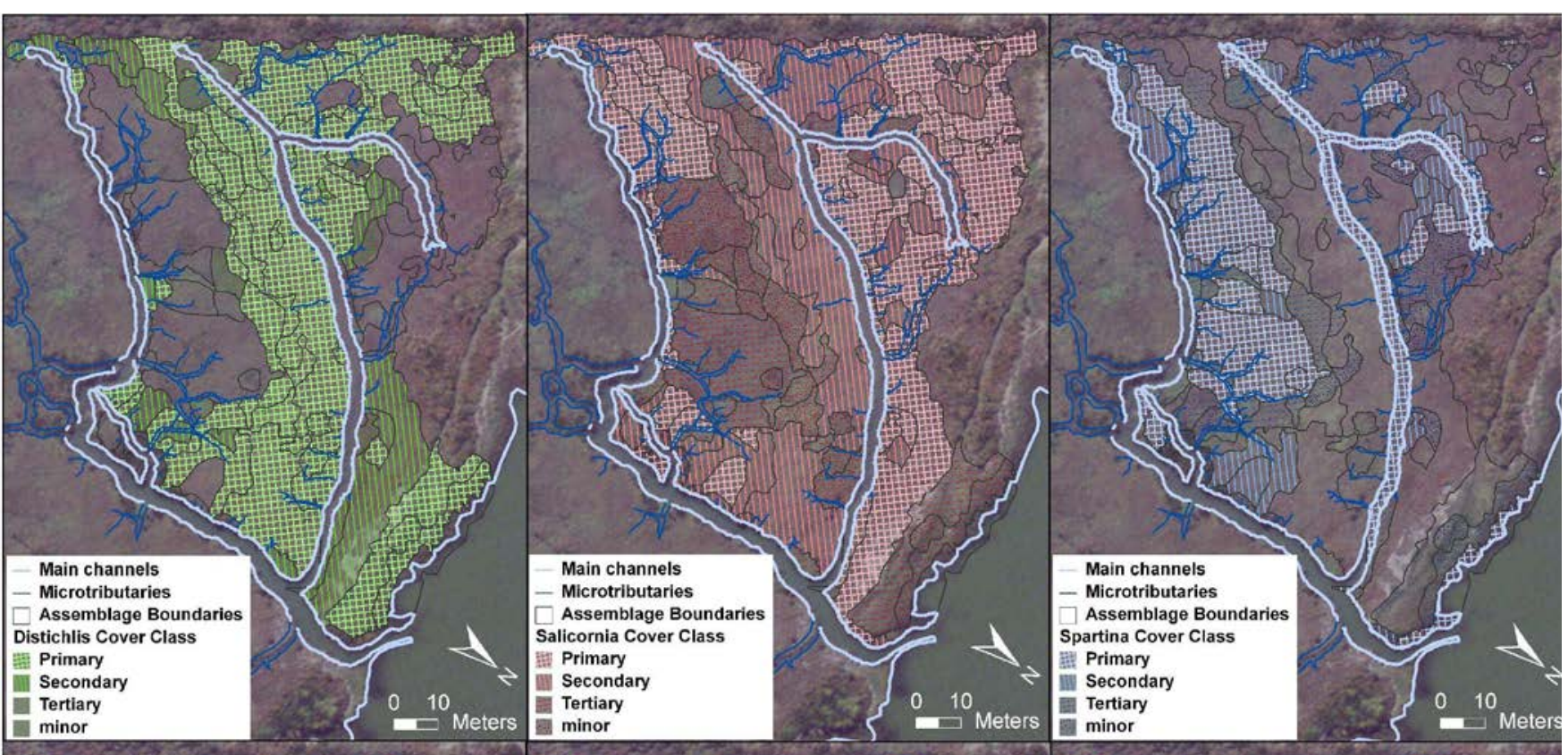

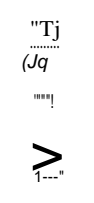

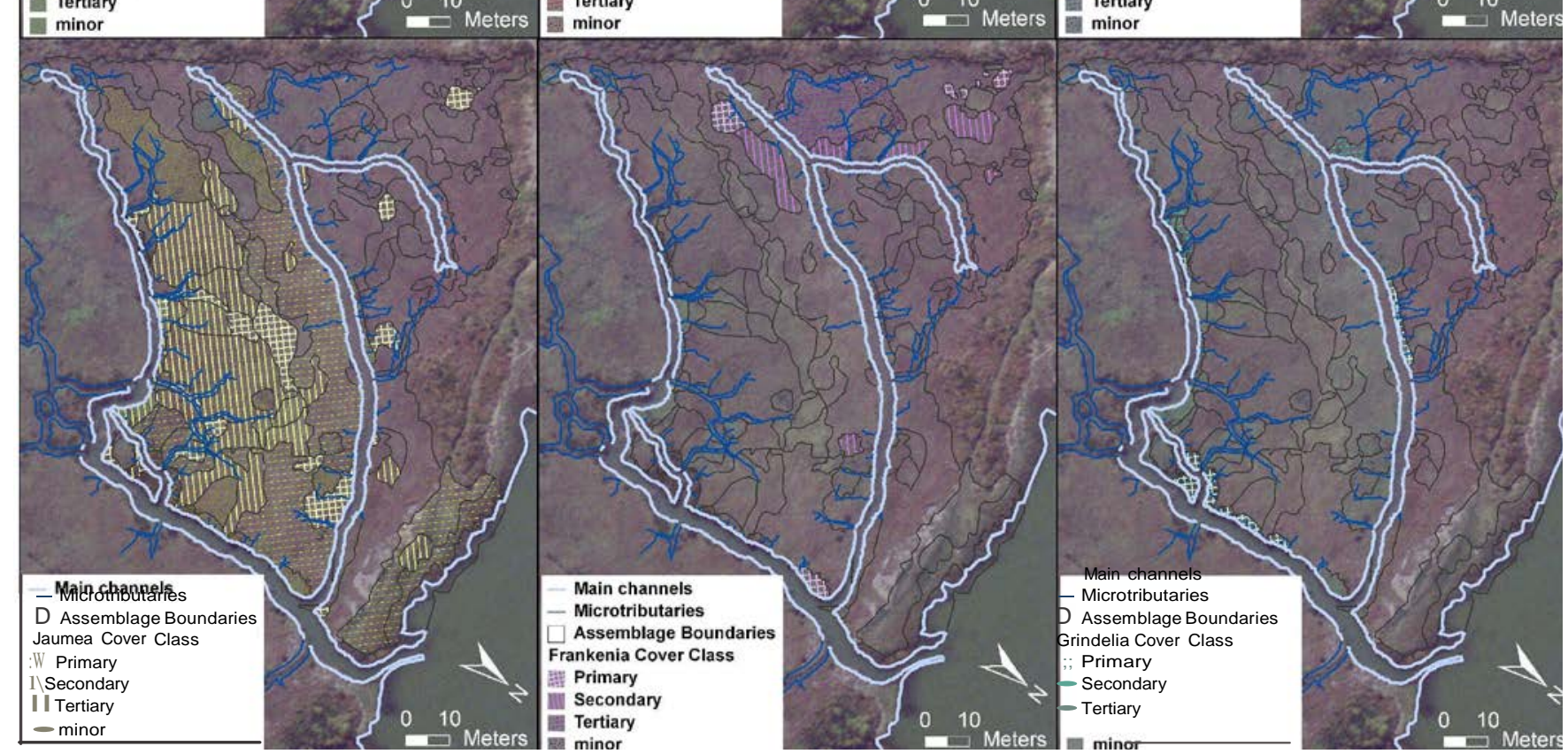


Salt marsh spatial patterns and zonation

Moffett, Robinson, Gorelick

631

\begin{tabular}{|c|c|c|c|}
\hline \multirow[b]{2}{*}{ Property } & \multicolumn{2}{|c|}{ Sample Statistics } & \multirow{2}{*}{$\begin{array}{l}\text { Correlation } \\
\text { with ECa }\end{array}$} \\
\hline & Mean & $\begin{array}{l}\text { Standard } \\
\text { Deviation }\end{array}$ & \\
\hline Soil Paste Extract Electrical Conductivity ${ }^{\mathrm{i}}$ (ECe, dS/m) & 68.9 & 15.0 & 0.67 \\
\hline Soil Pore Water Electrical Conductivity ${ }^{\mathrm{ii}}$ (ECw, dS/m) & 57.2 & 7.0 & 0.53 \\
\hline Soil Volumetric Water $\mathrm{Co}^{r}$. $\mathrm{tt}^{1}{ }^{\mathrm{\imath}}$ ) & 0.83 & 0.15 & 0.43 \\
\hline Soil Clay Content ${ }^{\mathrm{i}}(\%)$ & 61.8 & 9.4 & 0.51 \\
\hline Soil Temperature $\mathrm{iii}^{\mathrm{ii}}$ (dry conditions, ${ }^{\circ} \mathrm{C}$ ) & 13.98 & 0.54 & -- \\
\hline Soil Temperature ${ }^{\mathrm{iii}}$ (wet conditions, ${ }^{\circ} \mathrm{C}$ ) & 11.56 & 0.41 & -- \\
\hline Tide Water Electrical Conductivity $\left(\mathrm{EC}_{\mathrm{t}}, \mathrm{dS} / \mathrm{m}\right)$ & 33.4 & -- & -- \\
\hline${ }^{\mathrm{i}} \mathrm{N}=23,{ }^{\mathrm{ii}} \mathrm{N}=17,{ }^{\mathrm{iii}} \mathrm{N}=14$ & & & \\
\hline
\end{tabular}

632 